\title{
Adhesion Prevention in Laparoscopic Surgery
}

\author{
André Reis Correia, MD
}

\begin{abstract}
Background: Adhesions have important consequences for patients, surgeons, and health services. Peritonealtissue injury can be prevented by using careful surgical techniques. A large number of antiadhesion products have been used experimentally and clinically to prevent postoperative adhesions. Methods: The current author reviewed the surgical literature published about epidemiology, pathogenesis, and various prevention strategies of adhesion formation. Results: Meticulous surgery is essential to reduce unnecessary morbidity and mortality rates from these untoward effects of surgery. Several preventive agents against postoperative peritoneal adhesions have been investigated. Bioresorbable membranes are site-specific antiadhesion products but may be more difficult to use laparoscopically. Liquids and gels have the advantage of more-widespread areas of action and increased ease of use, particularly during laparoscopic operations. Effective pharmacologic agents that can reduce release of proinflammatory cytokines or activate peritoneal fibrinolysis are under development. Their results are encouraging but most of them are contradictory. Conclusions: Many modalities are being studied to reduce this risk; despite initial promising results of different measures in postoperative adhesion prevention, none of them have become standard applications. With the current state of knowledge, preclinical or clinical studies are still necessary to evaluate the effectiveness of the several proposed prevention strategies for avoiding postoperative peritoneal adhesions. ( J GYNECOL SURG 30:196)
\end{abstract}

\section{Introduction}

A DHESIONS ARE DEPOSITS OF FIBROUS TISSUE that occur within the body's cavities, such as the peritoneum, pericardium, or pleura. In the majority of patients, adhesions occur as a result of an injury to the lining membranes of the cavities. Peritoneal injury usually occurs as a result of surgery, peritonitis, or a combination of the two events.

Pelvic and abdominal adhesions have been associated with significant morbidity, including infertility, chronic pelvic pain, small-bowel obstruction, and difficulty with surgical access or surgical complications in the future. Adhesions result also in a large surgical workload and cost to health care systems. ${ }^{1-3}$ In a large review from Scotland, the total number of hospital admissions directly related to adhesions in 1994 was similar to the number of hip replacements, coronary-artery bypasses, appendectomies, or hemorrhoid operations. ${ }^{4}$

This current review of the literature discusses what is known about the epidemiology, pathogenesis, and strategies for preventing adhesion formation.

\section{Incidence of Adhesions}

It has been estimated that $90 \%$ of patients undergoing major abdominal surgery and 55\%-100\% of women un- dergoing pelvic surgery develop adhesions. ${ }^{5}$ It is generally believed that some people are more prone to develop postoperative adhesions than other people. Unfortunately, there is no available marker to predict the occurrence, or the extent and severity, of adhesions preoperatively. In addition, there are no available serum markers or imaging studies that are generally considered to be able to predict the incidence, severity, or extent of adhesions. Table 1 shows the incidences of postsurgical adhesions. ${ }^{6-8}$

Historically, it has been difficult to analyzing the literature on adhesion formation, because there is no single consistent model of adhesion formation, and no standard and reliable means of measuring this formation. A lack of standardization has made comparison of studies difficult.

\section{Pathogenesis of Adhesions}

Histopathologic studies have demonstrated a clear sequence of events from injury to the formation of adhesions. Peritoneal inflammation as result of an operative injury or peritonitis leads to the formation of an inflammatory exudate that contains strands of fibrin; vasoactive substances, such as histamines and kinins, are released by the disruption of stromal mast cells, increasing vascular permeability, which contributes to the collection of a fibrin-rich exudate that

Department of Gynaecology/Obstetrics-Hospital D. Estefânia, Centro Hospitalar de Lisboa Central, Lisbon, Portugal. 
Table 1. Incidence of Postsurgical Adhesions ${ }^{6-8}$

\begin{tabular}{lc}
\hline Procedure & $\%$ \\
\hline Adhesiolysis & $76 \%$ \\
Surgical treatment for endometriosis & $82 \%$ \\
Ovarian surgery & $75 \%$ \\
Myomectomy & $68 \%$ \\
Tubal surgery & $76 \%$ \\
\hline
\end{tabular}

covers the injured area. During surgery, the mesothelial injury exposes a denuded and acellular surface that serves as the nidus for wound healing and/or tissue-tissue adhesion. This submesothelial damage and exposure of the matrix occurs with simultaneous activation of the coagulation cascade and deposition of fibrin at the site of injury. Under normal conditions, this fibrinous exudate serves as a platform for the progress of proper healing, but, under certain circumstances, the deposited fibrin can, instead, serve as a bridge between unrelated neighboring tissues. Within a short period of time, the wound and its surrounding area are invaded by inflammatory cells that migrate from the peritoneal vasculature or from the peritoneal fluid. The inflammatory exudate is initially composed of neutrophils; by 24 hours the predominant cell is the macrophage. Next, the injured wound surface is evenly reperitonealized by the combined effort of multiple foci of proliferating mesothelial cells. Reperitonealization continues for 7-10 days, during which time, the entire surface becomes covered by a continuous sheet of mesothelium. The presence of mesothelial cells at the wound site corresponds to progressive wound healing and/or fibrosis and the deposition of an extracellular matrix $(\mathrm{ECM})$ composed of fibronectin, hyaluronic acid, various glycosaminoglycans, and proteoglycans. As the cells realign, the temporary ECM molecules are replaced by more-permanent proteins, such as collagens, while revascularization continues. ${ }^{9}$

The balance between fibrin deposition and degradation is critical in determining normal peritoneal healing or adhesion formation. If fibrin is completely degraded, normal peritoneal healing will occur. In contrast, if fibrin is not completely degraded, it will serve as a scaffold for fibroblast and capillary deposits. This ECM is normally completely degraded by matrix metalloprotease, leading to normal healing. If this process is inhibited by tissue inhibitors of matrix metalloprotease, peritoneal adhesions will form. In addition, after elicitation of angiogenesis factors, such as vascular endothelial growth factors (VEGFs), proliferation of endothelial cells initiates the development of a vascular structure within the adhesion tissue, which has been universally claimed to be important in adhesion formation. ${ }^{10}$ The peritoneal plasminogen-activating activity (PAA) is reduced by mechanical or chemical injury to the peritoneum, with the release of proinflammatory cytokines that stimulate the production of plasminogen-activator inhibitors 1 and 2 $(\mathrm{PAI}-1 / 2) .{ }^{11}$

\section{Cofactors that contribute to adhesion formation}

Ischemia. Ischemia has been proposed as the most important insult that leads to adhesion development. It has been demonstrated that fibroblasts in adhesion tissues have a different phenotype (myofibroblasts) than do the normal peritoneal tissue fibroblasts. More importantly, it has been shown that conversion of these cells from the normal phenotype to the adhesion phenotype can be induced by hypoxia. ${ }^{12}$ Compared with peritoneal fibroblasts, adhesion fibroblasts have a significant increase in basal mRNA levels of collagen I, fibronectin, matrix metalloproteinase-1 (MMP-1), tissue inhibitor of metalloproteinase-1 (TIMP-1), transforming growth factor (TGF)- $\beta 1$, cyclooxygenase-2 (COX-2), and interleukin (IL)-10. ${ }^{12-16}$ Tissue plasminogen activator (tPA) and PAI-1 are intracellular enzymes found in the peritoneal mesenchymal cells. These are involved in the intrinsic protective fibrinolytic activity of fibroblasts. The tPA/PAI-1 ratio has been shown to be $80 \%$ higher in normal peritoneal fibroblasts than in adhesion fibroblasts. Under hypoxic conditions, this ratio significantly decreases in normal and adhesion fibroblasts. ${ }^{13}$ MMPs and TIMPs are crucial proteolytic enzymes in the extracellular matrix remodeling process of healing. Hypoxia has been shown to inhibit MMP-1 and MMP-9 and augment TIMP-1 expression. This decrease in the MMP/TIMP-1 ratio during hypoxia may favor an increase in extracellular matrix production, and a decrease in turnover and degradation that may lead to tissue fibrosis and adhesion development. ${ }^{14-16}$ COX-2 has been shown to have an important role in the regulation of inflammation and angiogenesis. In adhesion fibroblasts, the expression of COX-2 is significantly increased, compared with that of normal fibroblasts. ${ }^{17}$ COX-2 inhibitors, such as celecoxib, tenoxicam, have been reported to reduce postoperative adhesions through their antiangiogenic, antiinflammatory, and antioxidant effects in animal studies. ${ }^{18-19}$

Pneumoperitoneum. This is a cofactor in adhesion formation, because adhesions have been shown in animal models to increase with the duration of the pneumoperitoneum and with insufflation pressure. ${ }^{21,22} \mathrm{CO}_{2}$ pneumoperitoneum induces adverse effects, such as hypercarbia, acidosis, hypothermia, and desiccation ${ }^{23,24}$; and alters peritoneal fluid and the morphology of the mesothelial cells. ${ }^{25,26}$

Pelvic inflammatory disease and endometriosis. It is recognized that pelvic inflammatory disease and endometriosis are additional potential causes of adhesions. ${ }^{27}$

Reactive oxygen species. Reactive oxygen species (ROS) are produced in a hyperoxic environment and during the ischemia/reperfusion process. ROS activity is injurious to cells, which protect themselves with an antioxidant system known as ROS scavengers. Recent data also point to a role for ROS in adhesion formation, because the administration of ROS scavengers has decreased adhesion formation in several animal models. ${ }^{10}$ ROS activity increases during both laparotomy and laparoscopy.

Tissue drying during surgery. This increases adhesions formation; intentional drying of the tissues, is an otherwise desirable procedure to aid the surgeon's view of the area but increases the risk of adhesion formation. Laparotomy is more likely to produce adhesions than laparoscopy. ${ }^{28,29}$ 


\section{Types of intraperitoneal adhesions}

Two types of adhesion formation are recognized and have been classified are de novo adhesions (type 1) and reformed adhesions (type 2). Table 2 shows the classification of postoperative adhesion development.

\section{Modes of Adhesion Prevention}

A number of approaches are being developed to reduce the incidence and severity of postoperative intra-abdominal adhesions, with variable degrees of success. Some of these approaches are site-specific to prevent localized adhesive disease, while others work in a generalized fashion to prevent adhesions throughout the peritoneal cavity.

Over the years, several measures-including microsurgical procedures, specialized equipment, unpowered gloves, extensive irrigations, adhesion-reducing agents such as antiinflammatory agents, peritoneal instillates, and surgical barriers-have been used to in attempts to prevent adhesions. Among these measures, some barriers have proved beneficial, but none of them have been found to prevent adhesion development completely in all patients.

Current modes of adhesion prevention include:

- Careful surgical technique and minimally invasive surgery whenever possible to reduce tissue injury

- Gelatinous/viscous liquids or bioresorbable membrane barriers to separate damaged peritoneal surfaces

- Pharmacologic agents that reduce the peritoneal inflammatory reaction and cytokine release

- Products that stimulate peritoneal fibrinolytic activity to enhance lysis of adhesion in the fibrinous stage.

\section{Meticulous surgical technique}

Meticulous surgical technique is an important part of adhesion prevention. The principle is to minimize peritoneal injury by careful handling of tissues, and precise alignment and approximation of tissue planes. Avoidance of tissue trauma, with gentle handling and prevention of thermal injury, meticulous hemostasis, prevention of bacterial infection or fecal contamination, use of copious irrigation, and

Table 2. Classification of Postoperative Adhesion DEVELOPMENT

\begin{tabular}{l|l}
\hline \multicolumn{1}{l}{ Type \# } & \multicolumn{1}{c}{ Descriptions } \\
\hline Type 1 & $\begin{array}{l}\text { De novo adhesion formation } \\
\text { A. No operative procedure at site of adhesion } \\
\text { formation } \\
\text { B. Operative procedure performed at site of } \\
\text { adhesion formation }\end{array}$ \\
\hline Type 2 & $\begin{array}{l}\text { Adhesion reformation; redevelopment of ad- } \\
\text { hesions at sites at which adhesiolysis was } \\
\text { performed } \\
\text { A. No operative procedure at site of adhesion } \\
\text { reformation (other than adhesiolysis) } \\
\text { B. Operative procedure performed at site of } \\
\text { adhesion reformation (in addition to } \\
\text { adhesiolysis) }\end{array}$ \\
\hline
\end{tabular}

Source: Diamond MP, Nezhat F. Adhesions after resection of ovarian endometriomas. Fertil Steril 1993;59:934. avoidance of foreign objects intuitively make sense as intraoperative means of preventing postoperative adhesions. ${ }^{30}$ Whenever possible, all diseased and necrotic tissue should be excised. Nonreactive suture material, such as polyglactin (Vicryl®), should be used, whereas using reactive material, such as catgut, should be discouraged.

Access. The issue of whether laparoscopic surgery resulted in fewer adhesions, compared to open laparotomy, has been assessed. Diamond et al. ${ }^{31}$ found that the incidence of de novo adhesion formation was lower when surgery was performed laparoscopically, compared to laparotomy. In addition, various advantages of this surgical approach have made it more popular. These include: smaller skin-incision size; early return of bowel function and ambulation; less bleeding; and shorter hospital stay. As the peritoneal cavity is normally sterile, warm, and wet, peritoneal injury during laparoscopy may be minimized further by using filtered, heated, and hydrated insufflating gas instead of the currently used unconditioned dry gas.

In an attempt to prevent postoperative permanent fibrotic adhesions, some surgeons have used a second-look laparoscopy within 6 weeks following surgery to evaluate and lyse soft intraperitoneal adhesions. The evidence supporting this approach comes mainly from postoperative studies of uterine myomectomy or pelvic adhesiolysis for infertility. ${ }^{32,33}$ Further clinical studies and randomized trials are required before this approach can be considered a proven method.

Peritoneal closure. Peritoneal closure is associated with slightly longer operating and postoperative times, greater postoperative pain, and more adhesions. ${ }^{34}$

\section{Antiadhesion adjuvants}

The pathogenesis of adhesion formation should direct surgeons toward the best adhesion-preventing techniques. While meticulous microsurgical technique should be maintained, there are new modalities that can aid in adhesion prevention. A number of products - in liquid, gel, or membrane forms - have been used clinically during abdominal and pelvic operations to act as barriers to prevent adhesion formation. The ideal product should be nonreactive but protect tissue at risk during the critical wound-healing period before being resorbed and cleared. The product should remain adherent to the target tissue and be easily applicable during laparoscopic procedures performed on adhesiogenic organs, such as adnexa, and remain active in the presence of blood. No such product is currently available.

Mechanical barriers are available in two forms: (1) freefloating abdominal instillates or (2) membrane barriers. Both prevent adhesion formation by preventing tissue apposition during the period of peritoneal repair and adhesion development.

Mechanical barriers: Intraperitoneal solutions. There are several abdominal instillates previously utilized in adhesion prevention, which are currently no longer as crystalloids and dextran 70 .

Crystalloids-Cristalloids, such as normal saline and Ringer's lactate, were used to produce a hydroflotation 
effect by instilling $500 \mathrm{~mL}$ to $3 \mathrm{~L}$ of fluid into the peritoneal cavity at the end of surgery. Irrespective of the volume instilled, the absorption rate by the peritoneum ensured that all the fluids were reabsorbed into the vascular circulation in 24-48 hours, but this was too short an interval to prevent adhesion formation. ${ }^{35}$

Dextran-Dextran is a water-soluble glucose polymer originally used as a plasma expander. Hyperosmolar solutions as Hyskon ${ }^{\circledR}$ (32\% dextran in $10 \%$ dextrose solution), were absorbed in 5-7 days and worked by mechanical separation of serosal membranes through hydroflotation and producing a "siliconizing" effect. ${ }^{35}$ Dextran has also an antithrombotic activity that retards adherence of blood clots and deposition of fibrin matrix. Serious side-effects have been reported that include coagulopathy, anaphylaxis, and ascites. Dextran has not been approved for use as an antiadhesive agent.

Hydrogel_Sprayable hydrogel, SprayGel ${ }^{\circledR}$ (Confluent Surgical, Waltham, MA), is a gel-based adhesion barrier. It is a hydrophilic polyethylene glycol barrier formed by combining two streams of liquid polymers, delivered via a catheter to the target tissue. When combined, the two streams produce a bright-blue solid polymer within minutes. SprayGel hydrogel can be applied during laparoscopy easily. After 5 days, the hydrogel layer is reabsorbed and undergoes renal clearance. In a European, multicenter randomized study, Mettler et al., ${ }^{36}$ evaluated 66 women who underwent myomectomy with or without SprayGel application. When compared with initial surgery, the mean adhesion tenacity score of adhesion seen at a second-look laparoscopy was $64.7 \%$ lower in patients receiving the adhesion barrier than in control patients (0.6 versus 1.7$)$. Compared with initial surgery, in the adhesion-barrier recipients versus the controls, respectively, the mean adhesion extent scores at second-look laparoscopy were 4.5 versus $7.2 \mathrm{~cm}^{2}$, and the mean adhesion incidence scores were 0.64 versus 1.22 . There were no adverse effects attributed to the adhesion barrier.

Icodextrin solution-A relatively new agent, an icodextrin Solution, Adept ${ }^{\circledR}$ (Baxter, Deerfield, IL), has been approved by the Food and Drug Administration to be used in laparoscopy and holds promising results as an adhesionpreventing agent. It is a $4 \%$ icodextrin solution that is sterile and clear. The solution is a colorless-to pale-yellow fluid that prevents adhesion formation by acting as a physical separation of the peritoneal surfaces during the early phases of natural healing. The presence of weight-molecular species of icodextrin, which are not easily absorbed, justifies its ability to maintain a reservoir of fluid in the peritoneal cavity via colloidal osmosis. In 2007, in the largest prospective randomized double-blinded study to date, icodextrin $4 \%$ has been shown to be safe and to result in a significant reduction of incidence, severity, and extent of adhesions. In addition, the study showed that this solution prevents deterioration of preexisting adhesions. ${ }^{37}$

Mechanical barriers: Membrane form. There has been particular interest in recent years in the use of absorbable or nonabsorbable membranes that are applied topically to separate traumatized peritoneal surfaces and prevent adhesion formation or reformation. The critical period for the action of these compounds is the first 5-7 days following injury. Many different mechanical barriers have been tried, but they are generally inadequate, because they interfere with blood supply or produce foreign-body reactions. Unlike their liquid counterparts, membrane forms prevent adhesions only in their areas of application. The membranes most commonly used are Interceed ${ }^{\circledR}$ (Johnson \& Johnson Medical, Summevile, NJ), Seprafilm ${ }^{\circledR}$ (Genzym Corporation, Cambridge, MA), and Gore-Tex ${ }^{\circledR}$ Surgical Membrane (W.L. Gore \& Associates, Inc., Flagstaff, AZ).

Oxidized regenerated cellulose-Interceed is gelatinous material, made of oxidized regenerated cellulose, which is absorbed slowly from the peritoneal cavity over 28 days. A meta-analysis of 11 relevant randomized controlled trials (RCTs) has shown that the barrier was safe and was associated with a reduced incidence of pelvic adhesion formation, both new formation and reformation, following laparoscopic surgery ${ }^{38}$ The benefit of Interceed was also supported by multicenter studies in Japan (laparotomy) and Germany (laparoscopic surgery) ${ }^{39,40}$; its use was associated with a reduced incidence of pelvic-adhesion formation following laparoscopy and laparotomy. Interceed is available in sheets measuring $1.5 \times 2$ inches or $3 \times 4$ inches. After application, it becomes a viscous gel that is completely absorbed in 4 weeks. The smaller size is appropriate for laparoscopic placement. This product is a procoagulant and can induce fibrin deposition in the presence of blood within the peritoneal cavity, so complete hemostasis is required before topical application. It is important to apply the product in single layers, interposed between adjacent anatomical structures at risk for adhesion. It is contraindicated for use in the presence of ongoing infection in the pelvic or abdominal cavities.

Expanded polytetrafluoroethylene-Expanded polytetrafluorethylene membrane (Gore-Tex) is a nonabsorbable and nonreactive membrane that has been used to repair both the pericardium and peritoneum. This product's effectiveness for preventing localized adhesion formation has been shown in two large prospective multicenter studies reported by the Surgical Membrane Study Group and the Myomectomy Adhesion Study Group. ${ }^{41,42}$ The disadvantages of this product are the permanent presence of a foreign body in the peritoneal cavity and the requirement for suture fixation of the membrane, which can be difficult during laparoscopy. A Cochrane Database review compared the use of Gore-Tex versus Interceed and controls in three studies on woman, following various gynecologic procedures via laparoscopy and laparotomy. Gore-Tex was found to be more effective than Interceed or no barrier for preventing adhesion formation. This superiority was confirmed with respect to size of adhesion area, tenacity, and vascularity, with significant improvement in total adhesion score. However, this product's usefulness is limited because it must be sutured in place and removed during a subsequent surgery. As a result of this, the use of this barrier has fallen out of favor in recent years. Nevertheless, studies have shown that removal of Gore-Tex at early second-look laparoscopy (11 days after myomectomy) was not associated with adhesions. ${ }^{37}$

Seprafilm-Seprafilm is a sterile translucent membrane comprised of sodium hyaluronate and carboxymethylcellulose, which temporarily separates potentially adherent surfaces, turning into a gel within 24 hours and covering serosal surfaces for 7 days. The product is excreted from the 
Table 3. Antiadhesion Products

\begin{tabular}{|c|c|c|c|c|c|}
\hline Products & Mode of action & Disavantages & Notes & $\begin{array}{l}\text { Clinical } \\
\text { effectiveness }\end{array}$ & Year \\
\hline Crystalloids & Hydroflotation of organs & Rapidly absorbed & $\begin{array}{l}\text { Absorption } \\
24-48 \mathrm{~h} \\
\text { Not approved } \\
\text { as AAA }\end{array}$ & $?$ & 2001 \\
\hline Dextran & Hydroflotation of organs & $\begin{array}{l}\text { Coagulopathy, anaphylaxis, } \\
\text { ascites (no longer used) }\end{array}$ & $\begin{array}{l}\text { Absorption } 7 \mathrm{~d} \\
\text { Not approved } \\
\text { as AAA }\end{array}$ & $+1-$ & 2001 \\
\hline Hydrogel & Absorbable gel barrier & - & Absorption $5 \mathrm{~d}$ & + & 2004 \\
\hline Icodextrin & Fluid barrier & - & $\begin{array}{l}\text { Not easily } \\
\text { absorbed }\end{array}$ & + & 2007 \\
\hline $\begin{array}{l}\text { Oxidized regenerated } \\
\text { cellulose }\end{array}$ & $\begin{array}{l}\text { Absorbable gelatinous } \\
\text { layer }\end{array}$ & $\begin{array}{l}\text { Requires complete } \\
\text { hemostasis }\end{array}$ & Absorption $4 \mathrm{w}$ & + & 2008 \\
\hline $\begin{array}{l}\text { Expanded } \\
\text { polytetrafluoroethylene }\end{array}$ & Mechanical barrier & $\begin{array}{l}\text { Permanent foreign body; } \\
\text { difficult to use in } \\
\text { laparoscopy; site-specific }\end{array}$ & Not absorbed & + & 1992/1995 \\
\hline Seprafilm $^{\circledR}$ & $\begin{array}{l}\text { Bioresorbable adherent } \\
\text { film }\end{array}$ & $\begin{array}{l}\text { Laparoscopic handling } \\
\text { limitations; site-specific }\end{array}$ & Absorption $4 \mathrm{w}$ & + & 1996 \\
\hline Oxiplex ${ }^{\circledR}$ & $\begin{array}{l}\text { Bioresorbable adherent } \\
\text { film }\end{array}$ & Limited data; site-specific & Absorption $6 \mathrm{w}$ & + & 2005 \\
\hline Pharmacologic agents & $\begin{array}{l}\text { NSAIDs } \\
\text { - Corticosteroids, } \\
\text { - Progesterone, } \\
\text { - Histamine } \\
\text { antagonists, } \\
\text { - Antioxidants } \\
\text { - Calcium- } \\
\text { channel-blocking } \\
\text { agents }\end{array}$ & $\begin{array}{l}\text { Efficacy in human } \\
\text { studies is sparse }\end{array}$ & & $?$ & \\
\hline
\end{tabular}

h, hours; d, days; w, weeks; AAA, antiadhesion agent; NSAIDs, nonsteroidal anti-inflammatory drugs.

body in $\sim 28$ days, and its use is not restricted in presence of blood. However, the product progressively loses its initial adherence and can migrate for some distance, thereby leaving a wound unprotected. It is difficult to manipulate during laparoscopy because of handling limitations; there are off-label reports of rolling Seprafilm in a wrap or making a slurry to make it applicable in laparoscopy. Conflicting studies exist regarding the product's effectiveness: The benefit of Seprafilm for reducing localized intra-abdominal adhesion formation in gynecologic surgery was demonstrated in two randomized controlled clinical trials, especially following myomectomies. ${ }^{43,44}$ However, Vrijland et al., found that Seprafilm decreased the severity but not the incidence of adhesions in a prospective study of patients undergoing a Hartmann procedure for diverticulitis or an obstructed rectosigmoid. ${ }^{45}$

Oxiplex $^{\circledR}$-Oxiplex (Frizomed, Inc. San Luis Obispo, $\mathrm{CA}$ ) is another promising membrane barrier undergoing investigation for gynecologic use. The product is specifically formulated for laparoscopic applications. It consists of a viscoelastic gel, composed of polyethylene oxide and carboxymethylcellulose, and is cleared by phagocytosis within 96 hours. It is a biocompatible resorbable film, with good handling properties and tissue adherence. The product is easily applied laparoscopically through a 5-mm trocar. The presence of blood at a membrane-tissue interface, although not studied directly, did not seem to affect the results. Oxiplex has been well-studied in rabbits and found to be promising for reducing postoperative adhesions. ${ }^{46-48}$ In another study, 49 patients had laparoscopic gynecologic surgery: 24 of 49 patients had surgery with viscoelastic (Oxiplex) gel placement on their adnexal area and the remaining 25 received only surgery. Treated adnexa had a decrease in American Fertility Society (AFS) score (11.99.1); in contrast, control adnexa had an increase in AFS score (8.8-15.8). This difference in second-look AFS score (42\% reduction) was significant. ${ }^{49}$

\section{Antiadhesion pharmacologic agents}

Systemically and orally specific inhibitors of adhesiogenesis are the goals of pharmaceutical research in this area. An increasing number of pharmacologic agents have been used to reduce the peritoneal inflammatory response to injury. These agents include corticosteroids, histamine antagonists, antioxidants, and calcium channel-blocking agents. The benefit of many of these agents has been demonstrated in animal studies, although proof of their efficacy in human studies is sparse. ${ }^{50,51}$ Many of these agents may be used systemically or topically, but the maintenance of a localized effect within the peritoneal cavity for a sufficient length of time to prevent adhesion formation has been a persistent problem. Other studies have been performed to manipulate coagulation mechanisms or to stimulate peritoneal fibrinolytic activity, with some success. Anticoagulation with warfarin or heparin is effective for preventing adhesion formation but carries a 
risk of intraperitoneal hemorrhage and is not in clinical use. There is some experimental evidence of localized reduction in adhesion formation with the use of some fibrinolytic enzymes such as streptokinase, urokinase, plasmin, and t-PA, especially when incorporated into a slow-release gel. Despite these results, there is little known about the pharmacokinetics of intraperitoneal administration and the proper dosage and length or treatment necessary.

Nonsteroidal anti-inflammatory drugs (local and systemic) have been studied for their possible antiadhesion benefits, by modifying arachidonic-acid metabolism and altering cyclo-oxygenase activities. Their clinical effectiveness is questionable because of inadequate concentrations at devascularized sites of surgical trauma. ${ }^{52}$

Progesterone has been used for preventing adhesion formation. This agent has shown to decrease the incidence of postoperative adhesions in animal models; this hypothesis, however, has never been proven in humans. ${ }^{53}$

Antibiotics are used for prophylaxis against postoperative infections and hence the inflammatory response; studies show that peritoneal irrigation with antibiotic solutions does not reduce adhesion formation. ${ }^{54}$ Table 3 summarizes information about some antiadhesions products.

\section{Conclusions}

Adhesions have important consequences for patients, surgeons. and health services. Operative injury and/or peritonitis leads to peritoneal inflammation and then to adhesions. Management of these adhesion-related clinical problems results in a large surgical workload and cost to the National Health Service, which emphasizes the importance of prevention. Many modalities are being studied to reduce this risk; despite initial promising results of different measures for postoperative adhesion prevention, none of them have become standard applications.

Peritoneal-tissue injury can be prevented by using a careful surgical technique. There is increasing evidence that use of laparoscopic procedures reduces the incidence of de novo and incisional adhesions. Knowledge of the risk factors, use of a good surgical technique to minimize tissue trauma, and use of proper instruments and ancillary technologies has been shown to decrease complications and the severity of adhesion formation.

A large number of antiadhesion products have been used experimentally and clinically to prevent postoperative adhesions. Bioresorbable membranes are site-specific antiadhesion products but may be more difficult to use laparoscopically. Liquids and gels have the advantages of more-widespread areas of action and increased ease of use, particularly during laparoscopic operations. Effective pharmacologic agents that can reduce release of proinflammatory cytokines or activate peritoneal fibrinolysis are under development. One key challenge is that these physical agents may reduce adhesions where they are placed but do not prevent adhesions developing elsewhere in the abdomen. The ideal adhesion-reduction agent should be easy to use for all type of surgical procedures and be capable of reducing adhesion formation at the operation sites and throughout the peritoneum. Box 1 summarizes the level of evidence for the various approaches. ${ }^{55}$ Further advances are likely to occur over the next few years.

\section{Box 1. Summary Statements (Quality of Evidence-Canadian Task Force)}

- Meticulous surgical technique is a means of preventing adhesions (II-2).

- The risk of adhesions increases with the total number of abdominal and pelvic surgeries performed on 1 patient (II-2).

- A polytetrafluoroethylene barrier is more effective than no barrier or oxidized regenerated cellulose in preventing adhesion formation (I).

- An oxidized regenerated cellulose barrier is associated with a reduced incidence of pelvic adhesion formation at both laparoscopy and laparotomy when possible hemostasis is achieved (II-2).

- Seprafilm is effective for preventing adhesion formation, especially following myomectomies (II-2).

- Various pharmacologic agents have been marketed as means of preventing adhesions. There is insufficient evidence for the use of pharmacologic agents for preventing adhesions (IIIC).

- No adverse effects have been reported with the use of oxidized regenerated cellulose, polytetrafluoroethylene and Seprafilm (II-1).

Adapted from ref. 55.

\section{Disclosure Statement}

There are no conflicts of interests with respect to all of the authors.

\section{References}

1. Ellis H, Moran BJ, Thompson JN, et al. Adhesionrelated hospital admissions after abdominal and pelvic surgery: A retrospective cohort study. Lancet 1999;353: 1476 .

2. Scott-Coombes DM, Vipond MN, Thompson JN. Surgeon's attitudes to the treatment and prevention of abdominal adhesions. Ann Roy Coll Surg (England) 1993; 75:123.

3. Ray NF, Larsen JW Jr, Stillman RJ, et al. Economic impact of hospitalizations for lower abdominal adhesiolysis in United States in nineteen ninety eight. Surg Gynecol Obstet 1993;176: 271.

4. National Health Service in Scotland. Information and Statistics Division. Edinburgh: Scottish Health Statistics 1996.

5. Liakakos T, Thomakos N, Fine PM, Dervenis C, Young RL. Peritoneal adhesions: Etiology, pathophysiology, and clinical significance. Recent advances in prevention and management. Dig Surg 2001;18:260.

6. Nordic Adhesion Prevention Study Group. The efficacy of Interceed (TC7) for prevention of reformation of postoperative adhesions on ovaries, Fallopian tubes, and fimbriae in microsurgical operations for fertility: A multicenter study. Fertil Steril 1995;63:709.

7. Gehlbach DL, Sousa RC, Carpenter SE, Rock JA. Abdominal myomectomy in the treatment of infertility. Int $\mathrm{J}$ Gynaecol Obstet 1993;40:45. 
8. Franklin R; Ovarian Adhesions Study Group. Reduction of ovarian adhesions by the use of Interceed. Obstet Gynecol 1995;86:335.

9. DiZerega GS. Contemporary adhesion prevention. Fertil Steril 1994;61:219.

10. Binda MM, Molinas CR, Koninckx PR. Reactive oxygen species and adhesion formation: Clinical implications in the adhesion prevention. Hum Reprod 2003;18:2503.

11. Vipond MN, Whawell SA, Thompson JN, et al. Peritoneal activity and intra-abdominal adhesions. Lancet 1991;i:1120.

12. Saed GM, Diamond MP. Molecular characterization of postoperative adhesions: The adhesion phenotype. J Am Assoc Gynecol Laparosc 2004;11:307.

13. Saed GM, Munkarah AR, Diamond MP. Cyclooxigenase-2 is expressed in human fibroblasts isolated from intraperitoneal adhesions but not from normal peritoneal tissues. Fertil Steril 2003;79:1404.

14. Saed GM, Diamond MP. Modulation of the expression of tissue plasminogen activator and its inhibitor by hypoxia in human peritoneal and adhesion fibroblasts. Fertil Steril 2003;79:164.

15. Sandell LJ. Genes and gene regulation of extracellular matrix proteins: An introduction. Connect Tissue Res 1996; $35: 1$.

16. Saed GM, Zhang W, Chegini N. Transforming growth factor beta isoforms production by human peritoneal mesothelial cells after exposure to hypoxia. Am J Reprod Immunol 2000;43:285.

17. Idell S, Zwieb C, Boggaram J. Mechanisms of fibrin formation and lysis by human lung fibroblasts: Influence of TGF-beta and TNF-alpha. Am J Physiol 1992;263(4[pt1]):L487.

18. Saed GM, Munkarah AR, Abu-Soud HM, Diamond MP. Hypoxia upregulates cyclooxygenase- 2 and prostaglandin $\mathrm{E}(2)$ levels in human peritoneal fibroblasts. Fertil Steril 2005;83(suppl1):1216.

19. Greene AK, Alwayn IP, Nose V. Prevention of intraabdominal adhesions using the antiangiogenic COX-2 inhibitor celecoxib. Ann Surg 2005;242:140.

20. Ezberci F, Bulbuloglu E, Ciragil P. Intraperitoneal tenoxicam to prevent abdominal adhesion formation in a rat peritonitis model. Surg Today 2006;36:361.

21. Molinas CR, Koninckx PR. Hypoxaemia induced by $\mathrm{CO}_{2}$ or helium pneumoperitoneum is a co-factor in adhesion formation in rabbits. Hum Reprod 2000;15:1758.

22. Molinas CR, Mynbaev O, Pauwels A, Novak P, Koninckx PR. Peritoneal mesothelial hypoxia during pneumoperitoneum is a cofactor in adhesion formation in a laparoscopic mouse model. Fertil Steril 2001;76:560.

23. West MA, Hackam DJ, Baker J, et al. Mechanism of decreased in vitro murine macrophage cytokine release after exposure to carbon dioxide: Relevance to laparoscopic surgery. Ann Surg 1997;226:179.

24. Gray RI, Ott DE, Henderson AC, et al. Severe local hypothermia from laparoscopic gas evaporative jet cooling: A mechanism to explain clinical observations. JSLS 1999; 3:171.

25. Hazebroek EJ, Schreve MA, Visse P, et al. Impact of temperature and humidity of carbon dioxide pneumoperitoneum on body temperature and peritoneal morphology. J Laparoendosc Adv Surg Tech A 2002;12:355.

26. Ott DE. Laparoscopy and tribology: The effect of laparoscopic gas on peritoneal fluid. J Am Assoc Gynecol Laparosc 2001;8:117.

27. Lower AM, Hawthorn RJS, Ellis H, O'Brien F, Buchan S, Crowe AM. The impact of adhesions on hospital read- missions over ten years after 8849 open gynaecological operations: An assessment from the Surgical and Clinical Adhesions Research Study. BJOG 2000;107:855.

28. Khaitan E, Scholz S, Richards WO. Laparoscopic adhesiolysis and placement of Seprafilm: A new technique and novel approach to patients with intractable abdominal pain. J Laparoendosc Adv Surg Tech A 2002; $12: 241$.

29. Kavic SM. Adhesions and adhesiolysis: The role of laparoscopy. JSLS 2002;6:99.

30. Haney AF, Hesla J, Hurst BS, et al. Expanded polytetrafluoroethylene (Gore-Tex Surgical Membrane) is superior to oxidized regenerated cellulose (Interceed TC7 + ) in preventing adhesions. Fertil Steril 1995;63:1021.

31. Diamond MP, Daniell JF, Feste J, et al. Adhesion reformation and de novo adhesion formation after reproductive pelvic surgery. Fertil Steril 1987;47:864.

32. Ugur M, Turan C, Mungan T, et al. Laparoscopy for adhesion formation following myomectomy. Int $\mathrm{J}$ Gynaecol Obstet 1996;53:145.

33. Raiga J, Canis M, Le Boudec G, et al. Laparoscopic management of adnexal abscesses: Consequences of fertility. Fertil Steril 1996;66:712.

34. Tulundi T, Al-Jaroudi D. Non-closure of peritoneum: A reappraisal. Am J Obstet Gynecol 2003;189:609.

35. Johns A. Evidence-based prevention of post-operative adhesions. Hum Reprod Update 2001;7:577.

36. Mettler L, Audebert A, Lehmann-Willenbrock E, et al. A randomized, prospective, controlled, multicenter clinical trial of sprayable, site-specific adhesion barrier system in patients undergoing myomectomy. Fertil Steril 2004; 82:398.

37. Brown CB, Luciano AA, Martin D, et al. Adept (icodextrin $4 \%$ solution) reduces adhesions after laparoscopic surgery for adhesiolysis: A double- blind, randomized, controlled study. Fertil Steril 2007;88:1413.

38. Ahmad G, Duffy JM, Farquhar C, Farquhar C, Vail A, Vandekerckhove P, Watson A. Wiseman D. Barrier agents for adhesion prevention after gynaecological surgery. Cochrane Database Syst Rev 2008;2:CD000475.

39. Sekiba K; The Obstetrics and Gynaecology Adhesion Prevention Committee. Use of Interceed (TC7) absorbable adhesion barrier to reduce postoperative adhesion reformation in infertility and endometriosis surgery. Obstet Gynecol 1992;79:518.

40. Wallwiener D, Meyer A, Bastert G. Adhesion formation of the peritoneal and visceral peritoneum: An explanation for the controversy on the use of autologous and alloplastic barriers. Fertil Steril 1998;69:132.

41. Surgical Membrane Study Group. Prophylaxis of pelvic sidewall adhesion formation with Gore-Tex surgical membrane: A multicenter clinical investigation. Fertil Steril 1992;57:921.

42. Myomectomy Adhesion Study Group. An expanded polytetrafluoethylene barrier (Gore-Tex Surgical membrane) reduces post-myomectomy adhesion formation. Fertil Steril 1995;57:921.

43. Diamond MP; Seprafilm Adhesion Group. Reduction of adhesion after uterine myomectomy by Seprafilm membrane (HAL-F): A blinded, prospective, randomised multicenter clinical study. Fertil Steril 1996;66:904.

44. Becker JM, Dayton MT, Fazio VW, et al. Prevention of postoperative abdominal adhesion by a sodium hyaluronatebased bioresorbable membrane: A prospective randomized, 
double-blinded multicenter study. J Am Coll Surg 1996; 183:297.

45. Vrijland WW, Tseng LN, Eijkman HJ, et al. Fewer intraperitoneal adhesions with the use of hyaluronic acid-carboxymethylcellulose membrane: A randomized clinical trial. Ann Surg 2002;235:193.

46. Diamond MP, DeCherney AH, Linsky CB. Adhesion re-formation in the rabbit model horn model: I. Reduction with carboxymethylcellulose. Int J Fertil 1988; 33:372.

47. Diamond MP, DeCherney AH, Linsky CB. Assessment of carboxymethylcellulose and 32\% dextran 70 for preventions of adhesion in a rabbit uterine model. Int J Fertil 1988;33:278.

48. Liu LS, Berg RA. Adhesion barriers of carboxymethylcellulose and polyethylene oxide composite gels. J Biomed Mater Res 2002;63:325.

49. Lundorff P, Donnez J, Korell M, Audebert AJ, Block K, diZerega GS. Clinical evaluation of a viscoelastic gel for reduction of adhesions following gynaecological surgery by laparoscopy in Europe. Hum Reprod 2005;20:514.

50. DiZerga GS. Contemporary adhesion prevention. Fertil Steril 1996;66:712.
51. Wiseman D. Polymers for the prevention of surgical adhesions. In: Domb AJ, ed. Polymeric Site-Specific Pharmacotherapy. New York: John Wiley \& Sons, 1994:369.

52. Risberg B. Adhesions: Preventive strategies. Eur J Surg Suppl 1997:32:39.

53. Montanino-Oliva M, Metzeger DA, Luciano AA. Use of medroxyprogesterone acetate in the prevention of postoperative adhesions. Fertil Steril 1996; 65:650.

54. Rappaport WD, Holcomb M, Valente J, et al. Antibiotic irrigation and the formation of intraabdominal adhesions. Am J Surg 1989;158:435.

55. Robertson D, Lefebvre G, Leyland N, et al.; Society of Obstetricians and Gynaecologists of Canada. Adhesion prevention in gynaecological surgery [in English and French]. J Obstet Gynaecol Can 2010;32;598.

Address correspondence to: André Reis Correia, $M D$

Rua José Maria Nicolau Nunber 4 5oA 1500-374 Lisbon

Portugal

E-mail: andre_reis@portugalmail.pt 
Copyright of Journal of Gynecologic Surgery is the property of Mary Ann Liebert, Inc. and its content may not be copied or emailed to multiple sites or posted to a listserv without the copyright holder's express written permission. However, users may print, download, or email articles for individual use. 